\title{
Chapter 9: The transition to parenthood in Spain: adaptations to ideals
}

Marta Seiz, Irene Lapuerta, Teresa Martín- García, Jordi Monferrer, Teresa JuradoGuerrero and María José González

Monograph Chapter

Published in print:

28 Oct 2016

Category:

Monograph Chapter

DOI:

https://doi.org/10.4337/9781785366000.00020

Pages:

Marta-Dom'nguez-Folgueras (23 total)

Collection: Social and Political Science 2016

\begin{abstract}
The experience of the transition to parenthood in Spain in this edited volume is strongly influenced by the economic crisis, 2008-2014. The vast majority of the couples interviewed for this study spoke about the precariousness of the labour market, job insecurity and not being able to make ends meet on just one pay-check. When the interviewed Spanish parents-to-be added all the leaves they were entitled to - 16 weeks of maternity leave, two weeks of paternity leave, two to four weeks of breastfeeding leave and holiday leave - they ended up with approximately 6 months of paid leave. After that, in most cases, both parents had to return to paid work because of economic reasons. Despite most couples expressing reluctance to send under 1-year-olds to childcare centres, the interviewed parents-to-be planned to combine different kinds of care in the second half of the first year of their child's life. Mothers planned to take part-time parental leave while using childcare services and asking grandparents for help with the child during their paid work hours. Spanish ideals about good motherhood and fatherhood were still rather traditional. In the interviews, mothers were considered 'by nature' closer to the child and responsible for childcare. Yet, we also saw signs of the 'new fatherhood' ideal, constructed in opposition to previous generations of distanced fathers. Some men were willing to become very involved in childcare and planned to adapt their jobs. In addition, the economic crisis was mirrored in the emergence of a group of 'crisis dads', consisting of unemployed men who envisioned themselves as the main carer in response to not being able to be the main provider.
\end{abstract}

